\section{Comparison of Hexane Vapour Permeation in Two Different Polymeric Membranes via an Innovative In-line FID Detection Method}

\author{
Z. Petrusová,a," L. Morávková, ${ }^{\mathrm{a}}$ J. Vejražka, ${ }^{\mathrm{a}}$ \\ Z. Vajglová, ${ }^{a}$ J. C. Jansen, ${ }^{b, *}$ and P. Izák ${ }^{a}$ \\ anstitute of Chemical Process Fundamentals of the CAS, v.v.i., \\ Rozvojová 135, 16502 Prague 6, Czech Republic \\ 'Institute on Membrane Technology, ITM-CNR, \\ Via P. Bucci 17/C, 87036 Rende (CS), Italy
}

doi: 10.15255/CABEQ.2016.1017

Original scientific paper

Received: October 14, 2016

Accepted: May 30, 2017

\begin{abstract}
This manuscript presents a novel method for the analysis of vapour permeation through polymeric membranes based on in-line analysis of the permeate with an FID detector. The hexane vapour permeation was studied for two commercially available membranes, namely low-density polyethylene (LDPE) and thin-film-composite polyamide (PA) membrane. The hexane permeation was studied at temperatures of $25-45^{\circ} \mathrm{C}$, hexane vapour activity in the range of $0.2-0.8$ and trans-membrane pressures of $5-50$ $\mathrm{kPa}$. Two fundamentally different membranes were chosen to demonstrate the potential and sensitivity of the permeation apparatus. Upon increasing the temperature from 25 to $45{ }^{\circ} \mathrm{C}$, the flux in LDPE was found to increase almost fourfold over the whole activity range. The nonlinear increase of the flux with activity indicates plasticization of the polymer by hexane. Contrarily, the flux in the PA membrane increases almost linearly with activity, with only a minor upward curvature. Since the PA is far away from any phase transition, it is less temperature-dependent than LDPE. The activation energy for permeation demonstrates that the temperature dependence in the LDPE membrane is dominated by changes in diffusion, whereas it is dominated by changes in solubility in the PA membrane.
\end{abstract}

Key words:

sensitive permeation apparatus, low-density polyethylene, thin-film-composite membrane, gas/vapour separation, hexane permeation, in-line FID detection

\section{Introduction}

To avoid financial losses and waste of energy, hydrocarbons emitted into the atmosphere should be captured. Moreover, efficient capture of air pollutants secures a healthy environment. The capture of volatile organic compounds (VOCs) from air should be an efficient continuous process. The most widely used technique is the adsorption of VOCs on activated carbon or in a suitable solvent. Nevertheless, the absorption is a discontinuous process where periodic regeneration of the absorbent is needed and, therefore, it is connected with the risk of the rise of toxic waste dumps and wastewater production. In contrast, membrane separation represents a safer, continuous, and more advanced method. Since the separation is not a phase transition and does not require heat-cool cycles, membrane gas/ vapour separations are generally less energy-demanding. The main advantages offered by membrane processes are ${ }^{1-3}$ :

"Corresponding authors: petrusova@icpf.cas.cz,

johannescarolus.jansen@cnr.it
- modular design of the membrane system, allowing even small units to operate economically,

- simplicity of operation and possibility to start up and shut down quickly,

- environmental friendliness,

- energy efficiency

- continuous process,

- small footprint.

The investment costs of membrane units are higher than in the case of conventional separation methods. However, the operating cost is much lower in comparison with the classically used techniques. Recently, the development of more efficient technology has led to a new era in the commercial use of membrane separation ${ }^{4}$.

Transport of gases and vapours in dense polymeric membranes is usually governed by the solution-diffusion mechanism ${ }^{5}$, which involves three successive steps: sorption of the permeating species at the feed side of the membrane, diffusion across the thickness of the membrane, and fast desorption from the downstream side of the membrane. The 
permeation is driven by the difference between partial pressures of a species across the membrane. The choice of the experimental conditions should take into account that the process conditions can change the polymeric membrane properties due to swelling, plasticization and/or softening of the membrane, and subsequently cause problems with membrane stability ${ }^{1}$.

An organic vapour flux can be determined for a specific membrane by various experimental methods, for example, using a constant pressure/variable volume technique under a steady state ${ }^{6,7}$, fixed-volume pressure increase instrument ${ }^{8}$, analysis via a thermal conductivity detector (TCD) .

In the present work, an innovative approach based on measurement of the vapour concentration in the permeate stream, using a Flame Ionisation Detector (FID) is tested. The scope of this work is to study the hexane vapour permeation through two polymeric membranes, exploring the possible use of an FID detector directly incorporated in the permeation apparatus for an in-line analysis of the vapour permeation rate. For this purpose, the experimental study was carried out for two fundamentally different membrane types to explore the versatility and the sensitivity of the method.

\section{Experimental}

\section{Materials}

Chemicals were used without further purification as received: hexane $\geq 99.5 \%$ (p.a., Lachner, Neratovice, Czech Republic). The gas nitrogen used for permeation measurements (stated purity of $99.995 \%$ ) was supplied by Linde gas, Prague, Czech Republic.

Commercially available membranes were used for the permeation measurements, namely low-density polyethylene (LDPE) and thin-film-composite polyamide membrane (TFC PA). The low-density polyethylene membrane BRALEN FB 2-30 (Slovnaft, Bratislava, Slovakia) in the form of foil was used. The LDPE thickness of $49 \mu \mathrm{m}$ was measured by a micrometre Micromaster ${ }^{\circledR}$ Capausystem $\mathrm{IP}_{54}$ (Switzerland). The thin film composite polyamide membrane TM710D is originally commercialized as a Brackish Water RO Element and supplied by Toray Company in the form of a spiral wound module (supplied by Lenntech, Delft, Netherlands). The selective layer of PA is usually $1 \mu \mathrm{m}$ thick.

\section{Methods}

Hexane permeation experiments were carried out at three temperatures: $25^{\circ} \mathrm{C}, 35^{\circ} \mathrm{C}$ and $45^{\circ} \mathrm{C}$. For each temperature, three pressure differences be- tween the feed and permeate sides were applied: $\Delta p$ of 5,25 , and $50 \mathrm{kPa}$. The feed pressure was always kept at $100 \mathrm{kPa}$ (absolute), while the permeate pressure was 95,75 or $50 \mathrm{kPa}$ (absolute), respectively. The circular membrane samples had an exposed area of $40.7 \mathrm{~cm}^{2}$ within the footprint of the sealing rings. The temperature in the permeation cell was always higher than that in the saturator (the temperature difference was at least $5{ }^{\circ} \mathrm{C}$ ) to avoid unwanted vapour condensation. The feed flow of nitrogen and sweeping gas nitrogen flow was

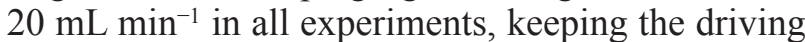
force constant.

The basic test apparatus (Figure 1) was described previously ${ }^{10,11}$, but has been significantly modified to extend the set of experimental data. The significant modification was based on the necessity of mass balance check. Newly, it is possible to analyse each stream (i.e. feed, retentate or permeate) and determine flow rates of both output streams (i.e. retentate and permeate). The VOC concentration in all streams (feed, retentate and permeate) can be measured directly using in-line FID (GowMac, Bethlehem, PA, USA). The apparatus offers two measurement modes, i.e. either vacuum mode or sweeping gas mode. Both experimental modes can be realised by recording of permeate pressure increase or via in-line FID analysis, respectively. The hexane flux through the membrane can also be measured using a cold trap connected to a vacuum pump for a given time. The condensed amount of hexane is then weighted and compared to the value determined using the in-line FID or permeate pressure increase experiment. The apparatus is shown in Figure 1. Each membrane sample was placed on a disc of sintered stainless steel in a cross-flow membrane cell. The custom-made cell has a special design that allows radial flow profiles in co-current and counter-current mode, and has been described elsewhere ${ }^{10,11,12}$.

The appropriate mixture of nitrogen with VOC vapour is prepared by bubbling nitrogen through a tempered glass one-stage custom made saturator until complete saturation of this stream, and subsequent mixing of this stream with a known amount of dry nitrogen until the desired activity. The total volume of the saturator is $250 \mathrm{~mL}$. The VOC concentration is controlled by adjusting the saturator temperature (a jacketed vessel with warm water circulation) and the mass flow controllers FC1, FC2, and FC3 (Bronkhorst). The feed mixture enters the membrane cell and passes through a $0.5 \mathrm{~mm}$ wide gap above the membrane, where it flows radially from the middle of the sample to the perimeter, ensuring a uniform flow above the membrane. The retentate leaves the cell via a back pressure controller PC1 (Bronkhorst) to a vacuum pump. The actual 


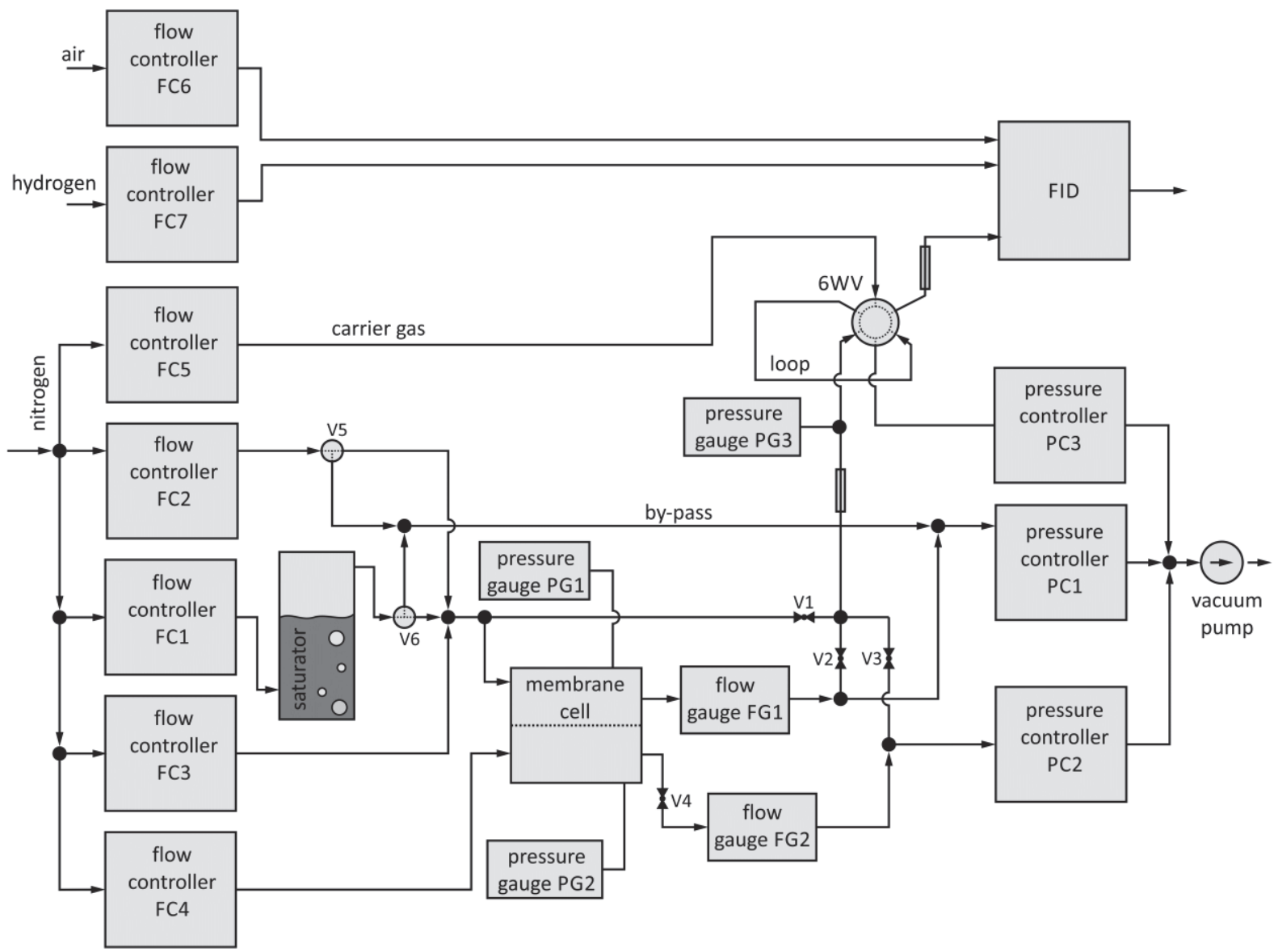

Fig. 1 - Scheme of the apparatus for vapour permeation experiments: $F C$ - flow controller, $F G$ - flow gauge, PC - back pressure controller, $P G$ - pressure gauge, $100 \mathrm{~mL}$ cylindrical vessel for nitrogen sweep before the six-port valve for FID detector, V-2-way or 3-way valve, 6WV - 6-way valve, FID - Flame Ionisation Detector, loop - $2920 \mu \mathrm{L}$ in-line sample loop; operating ranges of all $F C, F G, P C$, and $P G$ are summarized in Table 1

retentate and permeate pressures are measured by pressure gauge PG1 and PG2 (BD sensors), respectively.

The sweep gas (nitrogen) flows in the countercurrent arrangement. The flow-rate of the sweep gas and its pressure were controlled by flow and pressure controller FC4 and PC2 (Bronkhorst), respectively. The VOC content in the permeate was measured after flowing a sample via a restricting capillary (diameter of $100 \mu \mathrm{m}$, length of $100 \mathrm{~mm}$ ) through a measuring loop (volume of $2920 \mu \mathrm{L}$ ). The pressure in the loop was regulated by pressure controller PC3 (Bronkhorst) and checked by pressure gauge PG3 (BD sensors). Periodically, the content of the measurement loop was flushed into the FID by switching the 6-way valve, thus connecting the measurement loop to the FID. For the FID analysis of the VOC content in the loop, input flows of nitrogen, air, and hydrogen were adjusted appropriately by mass flow controllers FC5, FC6, and FC7 (Bronkhorst).

The permeation in a membrane was described by the solution-diffusion mode ${ }^{13}$. The vapour per- meations were expressed as permeances $P_{\mathrm{i}} / l$, defined as the permeation flow rate $Q_{\mathrm{i}}$ of a particular component, normalised by membrane area $A$ and by the difference in partial pressures, which represents the driving force:

$$
\frac{P_{\mathrm{i}}}{l}=\frac{Q_{\mathrm{i}}}{A\left(p_{\mathrm{i}, \text { feed }}-p_{\mathrm{i}, \text { perm }}\right)}\left[\frac{\mathrm{m}^{3}}{\mathrm{~m}^{2} \mathrm{~s} \mathrm{kPa}}\right]
$$

where, $p_{\mathrm{i} \text {,eed }}$ is the partial pressure of component $i$ on the feed-side and $p_{\mathrm{i}, \mathrm{perm}}$ is the partial pressure of component $i$ on the permeate-side. The permeance was expressed in the past in gas permeation units (GPU), recalculated from SI units as:

$$
\begin{aligned}
& 1 \mathrm{GPU}=1 \cdot 10^{-6} \frac{\mathrm{cm}^{3}(\mathrm{STP})}{\mathrm{cm}^{2} \mathrm{~s} \mathrm{cmHg}}= \\
& =2.70 \cdot 10^{-3} \frac{\mathrm{m}^{3}(\mathrm{STP})}{\mathrm{m}^{2} \mathrm{~h} \mathrm{bar}}=7.52 \cdot 10^{-12} \frac{\mathrm{m}^{3}(\mathrm{STP})}{\mathrm{m}^{2} \mathrm{~s} \mathrm{~Pa}}
\end{aligned}
$$

The permeances are discussed as a function of vapour activity, $a_{\mathrm{i}}$ that is calculated as follows: 


$$
a_{\mathrm{i}}=\frac{p_{\mathrm{i}}}{p_{\mathrm{i}}^{\mathrm{sat}}}[-]
$$

where $p_{\mathrm{i}}$ and $p_{\mathrm{i}}^{\text {sat }}$ are the $\mathrm{i}$-th component partial and saturated vapour pressures, respectively.

\section{Results and discussion}

\section{The permeation apparatus setup and calibration procedures}

All possible experimental modes of the permeation apparatus are summarised in Figure 2. The apparatus can be operated in a sweeping gas or vacuum mode. All the streams, i.e. feed, retentate and permeate, can be analysed in-line via the FID detector when the sweeping gas mode is applied. A further possibility is to carry out permeate pressure increase experiments with the closed valve V4 (Figure 1). Moreover, the permeation cell can be used both in co-current and in counter-current flow arrangement, which enables to study the different flow regimes. The gas mixtures were prepared by mixing different quantities of dry nitrogen and hexane-saturated nitrogen, obtained via bubbling through the saturator, adjusting the flow controllers (see Figure 1 and Table 1). The amount of liquid hexane in the saturator was maintained within 80 $160 \mathrm{~mL}$. The independence of the signal on the hexane level was verified via consecutive experiments at various liquid levels, obtaining the same FID signal and thus confirming complete saturation of the gas stream.

The experimental data were collected both from evaluation of in-line FID analyses and pressure increase rate measurements carried out after reaching steady state. The hexane vapour fluxes evaluated from these two methods were in good agreement, with an experimental error below $10 \%$.
Table 1 -Ranges of flow controllers, flow meters, pressure controllers, and pressure ganges in the modified permeation apparatus

\begin{tabular}{|c|c|c|}
\hline $\begin{array}{l}\text { Designa- } \\
\text { tion }\end{array}$ & $\begin{array}{l}\text { Function in the } \\
\text { experimental apparatus }\end{array}$ & Measuring range \\
\hline $\mathrm{FC} 1$ & $\mathrm{~N}_{2}$ flow through saturator & 0-20 mL(STP) $\mathrm{min}^{-1}$ \\
\hline $\mathrm{FC} 2$ & $\begin{array}{l}\text { dry } \mathrm{N}_{2} \text { diluting the saturated } \\
\text { stream }\end{array}$ & 0-200 mL(STP) $\mathrm{min}^{-1}$ \\
\hline FC3 & $\begin{array}{l}\text { dry } \mathrm{N}_{2} \text { diluting the saturated } \\
\text { stream }\end{array}$ & 0-20 mL(STP) $\mathrm{min}^{-1}$ \\
\hline $\mathrm{FC} 4$ & sweeping gas $\mathrm{N}_{2}$ & 0-20 mL(STP) $\mathrm{min}^{-1}$ \\
\hline FC5 & carrier gas to the FID detector & $0-500 \mathrm{~mL}(\mathrm{STP}) \mathrm{min}^{-1}$ \\
\hline FC6 & air into the FID detector & $0-500 \mathrm{~mL}(\mathrm{STP}) \mathrm{min}^{-1}$ \\
\hline FC7 & $\mathrm{H}_{2}$ into the FID detector & $0-100 \mathrm{~mL}(\mathrm{STP}) \mathrm{min}^{-1}$ \\
\hline FG1 & flow gauge of retentate & $\begin{array}{l}0-50 \mathrm{~mL}(\mathrm{STP}) \mathrm{min}^{-1} \\
\mathrm{~N}_{2} \text { equiv. }\end{array}$ \\
\hline FG2 & flow gauge of permeate & $\begin{array}{l}0-50 \mathrm{~mL}(\mathrm{STP}) \mathrm{min}^{-1} \\
\mathrm{~N}_{2} \text { equiv. }\end{array}$ \\
\hline $\mathrm{PC} 1$ & $\begin{array}{l}\text { pressure controller for } \\
\text { retentate stream }\end{array}$ & $0-300 \mathrm{kPa}(\mathrm{abs})$ \\
\hline $\mathrm{PC} 2$ & $\begin{array}{l}\text { pressure controller for } \\
\text { permeate stream }\end{array}$ & $20-100 \mathrm{kPa}(\mathrm{abs})$ \\
\hline PC3 & $\begin{array}{l}\text { pressure controller for loop } \\
\text { before FID }\end{array}$ & 4-20 kPa(abs) \\
\hline PG1 & $\begin{array}{l}\text { pressure gauge of retentate } \\
\text { stream }\end{array}$ & $0-300 \mathrm{kPa}(\mathrm{abs})$ \\
\hline PG2 & $\begin{array}{l}\text { pressure gauge of permeate } \\
\text { stream }\end{array}$ & $0-100 \mathrm{kPa}(\mathrm{abs})$ \\
\hline PG3 & $\begin{array}{l}\text { pressure gauge of loop } \\
\text { before FID }\end{array}$ & $0-100 \mathrm{kPa}(\mathrm{abs})$ \\
\hline
\end{tabular}

The ranges of flow and pressure controllers and gauges are specified in Table 1 . The accuracy of the flows and pressures were specified as follows:

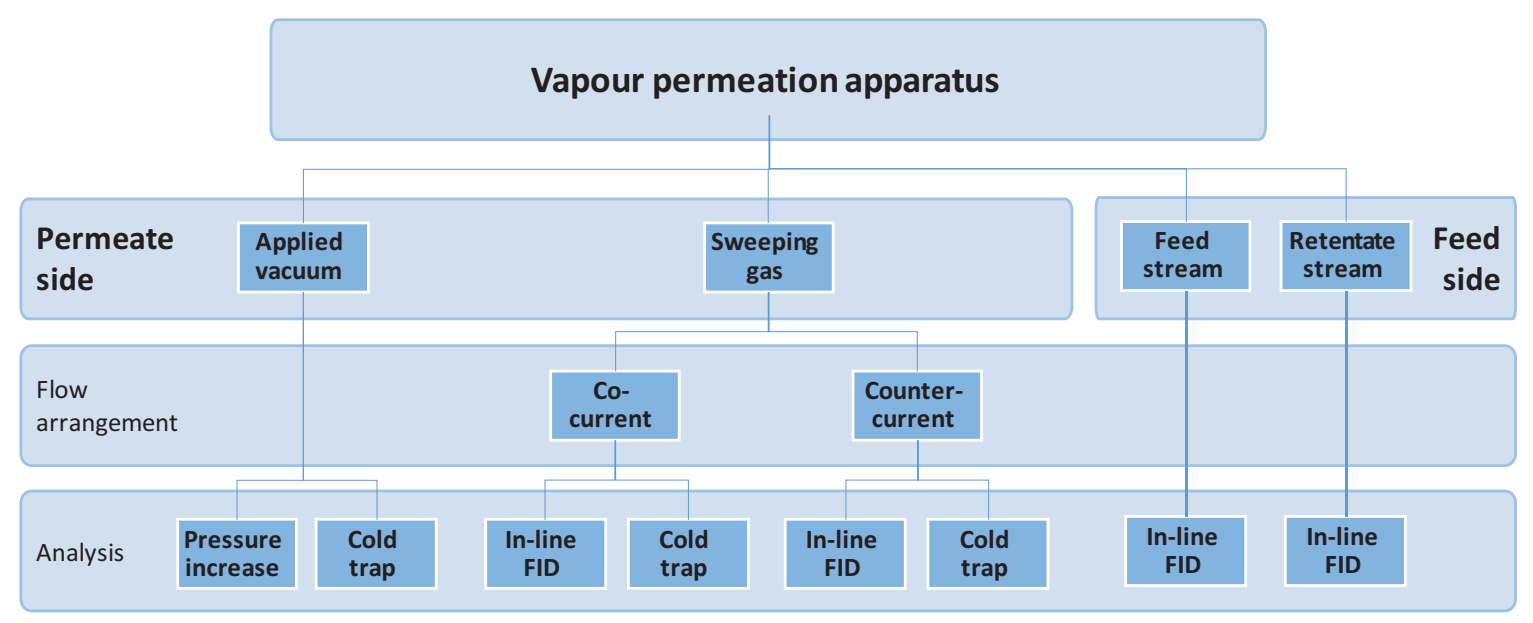

Fig. 2 - Scheme of possible experimental modes of vapour permeation apparatus 
$\pm(0.5 \% R d+0.1 \% F S)$ for a flow controller [mL(STP) $\left.\mathrm{min}^{-1}\right]$

$\pm(0.5 \% F S)$ for a pressure controller $[\mathrm{kPa}]$

where $R d$ is a read value, and $F S$ is the full scale of the controller.

All flow controllers were originally calibrated for pure nitrogen. Therefore, the calibration constant for hexane vapours was determined. The various flows of hexane vapour were adjusted by both the temperature of the saturator (within the range of $15-40{ }^{\circ} \mathrm{C}$ ) and the nitrogen flow bubbling through the saturator (within the range of 5-20 $\mathrm{mL}$ (STP) $\mathrm{min}^{-1}$ ). The calibration constant of hexane vapours was determined as $5.9 \mathrm{~mL}(\mathrm{STP}) \mathrm{min}^{-1}$. The constant approximately corresponds to a ratio between the heat capacity of hexane and nitrogen (which is circa 5.0) because the signal of the flow gauges is based on the measurement of changes in the heat capacity of a flowing stream.

The next necessary calibration was for the FID detector. The calibration of the FID signal was carried out similarly to the previously described calibration of the flow gauges. The FID signal was analysed for various hexane flows adjusted by different temperatures of the saturator, as well as different ratios of the hexane-saturated and the dry nitrogen stream in the mixture.

During preliminary tests, it was found that the decrease in temperature inside the tempered box led to a partial condensation of hexane vapours inside the tubing. For this reason, the entire setup was enclosed in a box tempered at temperature of $45^{\circ} \mathrm{C}$ higher than both the saturator and the cell temperature.

\section{Data evaluation}

The present experiments were carried out in the counter-current arrangement, which assured an approximately constant driving force across the membrane. This flow arrangement was chosen, based on a previous study of concentration profiles in the gas permeation cell ${ }^{13}$.

Firstly, the permeances were calculated with driving forces obtained as the difference of the partial pressures of hexane in the feed and in the permeate (Eq. (1)). Secondly, the permeances were calculated with a pressure difference calculated by the logarithmic average that is generally used in engineering applications for the driving force in the counter-flow arrangement:

$$
L_{\mathrm{pd}}=\frac{\left(p_{\mathrm{i}, \text { feed }}-p_{\mathrm{i} \text {,perm }}\right)-\left(p_{\mathrm{i} \text {,ret }}-p_{\mathrm{i}, \text { sweep }}\right)}{\ln \left(p_{\mathrm{i}, \text { feed }}-p_{\mathrm{i}, \text { perm }}\right)-\ln \left(p_{\mathrm{i}, \text { ret }}-p_{\mathrm{i} \text {, sweep }}\right)}
$$

where $L_{\mathrm{pd}}$ is the logarithmic average of the partial pressure difference of $i$-th component in the feed, sweep, retentate (denoted by subscript ret), and permeate (denoted by subscript perm) stream, respectively. For very low flow rates, $p_{\mathrm{i} \text {,perm }} \approx 0$ and $p_{\mathrm{i}, \text { feed }} \approx$ $p_{\mathrm{i}, \text { ret }}$, and both methods give approximately the same result.

The difference between the permeances of hexane vapour, calculated with the pressure driving force from either Eq. (1) or Eq. (4), were close to the experimental error, lower than $5 \%$ for LDPE and $10 \%$ for TFC PA membrane.

The permeation apparatus can determine either the transport of a species through the membrane (in the case of low membrane fluxes and corresponding low values of stage cut) or the maximal removal of organic vapours (in the case high membrane fluxes and hence high values of stage-cut). The stage-cut is defined as the percentage of a particular component in the feed stream, which permeates through the membrane:

$$
\theta_{\mathrm{i}}=\frac{Q_{\mathrm{i}, \text { membr }}}{x_{\mathrm{i}, \text { feed }} \cdot Q_{\text {feed }}} \cdot 100[\%]
$$

where $\theta_{\mathrm{i}}$ is the membrane stage-cut of $\mathrm{i}$-th component, $Q_{\mathrm{i} \text { membr }}$ is the flux of $\mathrm{i}$-th component through membrane and the term $\left(x_{\mathrm{i}, \text { feed }}, Q_{\text {feed }}\right)$ represents the quantity of $i$-th component in the feed stream.

A high stage-cut leads usually to a higher concentration of the gas in the permeate, and also to a retentate stream which is richer in the less permeable component. On the other hand, high stage-cut may also lead to a significant change in the driving force along the membrane because of a change in the vapour concentration in the stream. The stagecut for tested membranes and their dependence on the feed composition will be discussed herein.

\section{Membrane performance studies}

All permeation measurements were carried out from the lowest hexane vapour activity $(0.2)$ to the highest hexane vapour activity (0.85), and then decreasing back to the lowest vapour activity. Hysteresis, which would exceed experimental error, was not observed with any of the tested membranes.

The permeances will be discussed as a function of the hexane vapour activity defined by Eq. (3), the cell temperature and the trans-membrane pressure. The temperature dependence of the permeance coefficient $P_{\mathrm{i}} / l$ obeys the Arrhenius rule:

$$
P=P_{0} \cdot \exp \left[\frac{E_{\mathrm{p}}}{R T}\right]
$$

where $P_{0}$ is the pre-exponential constant. The value of activation energy for permeation $E_{\mathrm{p}}$ is obtained from the slope in a plot displaying logarithm of the permeance coefficient versus the reciprocal value of the absolute temperature. The temperature depen- 

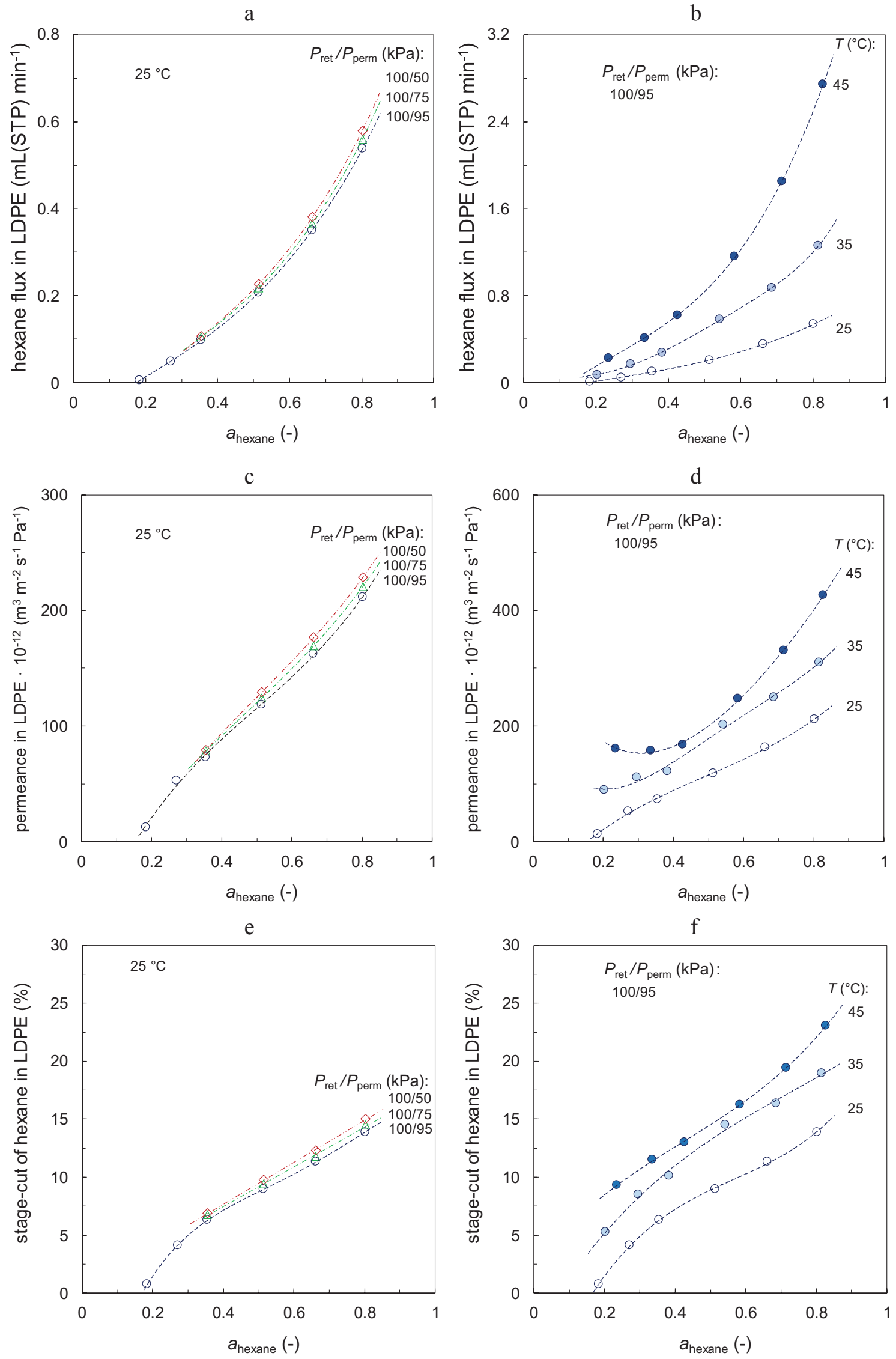

Fig. 3 - Results of permeation experiments with LDPE membrane: $a$, b) Hexane flux as a function of the hexane activity, temperature and trans-membrane pressure; $c, d)$ Hexane permeance as a function of the hexane activity, temperature and trans-membrane pressure; e, f) Hexane stage-cut as a function of the hexane activity, temperature and trans-membrane pressure; The lines are intended as a guide to the eye. 
dence of permeation involves counteracting effects of decreasing solubility with increasing diffusivity as the temperature increases, and the balance between the two effects determines the final result.

\section{Low density polyethylene (LDPE) membranes}

An overview of the hexane trans-membrane flux is shown in Figure 3a, b, and Figure S1. Interestingly, the flux is almost independent of the permeate pressure, and thus also of the trans-membrane pressure, with only a minor increase in the flux with permeate pressure. On the other hand, for any given activity, the flux increases almost fourfold upon increasing the temperature from $25{ }^{\circ} \mathrm{C}$ to $45{ }^{\circ} \mathrm{C}$ (see Figure $3 \mathrm{~b}$ and Figure S1). This can be attributed to the softening of the amorphous phase of the semi-crystalline LDPE, and possibly also due to a slight melting of the crystalline phase upon heating. The nonlinear increase in the flux with activity indicates strong plasticization of the polymer by hexane.

The latter is confirmed by the strong increase in the permeance with increasing activity (Figure $3 \mathrm{c}, \mathrm{d}$ and Figure S2). Only at the highest temperature and at low activity, the permeance has a constant value because of the more rubbery nature of the polymer at $45^{\circ} \mathrm{C}$, which is hardly plasticized by the low hexane concentrations.

Figure 3e, f and Figure S3 show the stage-cut (i.e. percentage of hexane removal) under the given conditions. The stage-cut generally increases with increasing temperature and activity of permeating components. At $45{ }^{\circ} \mathrm{C}$ and activity 0.85 , nearly $25 \%$ of the hexane is transferred from the feed stream to the permeate stream in a single passage. This shows that the PE membrane is highly efficient for the given case-study separation. The high stage-cut complicates the accurate quantitative evaluation of the membrane permeability, because the feed (or retentate) concentration is no longer constant, and the change in the hexane concentration at the permeate side of the membrane is also no longer negligible. Nevertheless, for a qualitative description of the membrane performance and for the present feasibility study of the use of the FID to determine the membrane permeability, this is not a problem.

\section{Polyamide thin film composite membrane}

Analogous to the LDPE film, a thin film composite polyamide film (TFC PA) was tested. An overview of the hexane trans-membrane flux is shown in Figure 4a, b and Figure S4 and permeance is shown in Figure 4c, $d$ and Figure S5, respectively. In the TFC PA, the flux increases almost linearly with activity, with a slight upward curvature. Since the PA skin layer on the support membrane is far away from any phase transition, its temperature dependence is weaker than in the case of LDPE.

The PA membranes have a 1-2 order of magnitude lower permeability than LDPE, assuming a PA layer thickness of about $1 \mu \mathrm{m}$, which is typical for TFC PA membranes. However, owing to much smaller thickness (PA and LDPE thickness was 1 $\mu \mathrm{m}$ and $49 \mu \mathrm{m}$, respectively) it reaches a similar percentage of hexane removal from the feed stream. This suggests that thinner LDPE films would be able to reach an even higher percentage of hexane removal from the feed stream. The permeance of PA is much less dependent on the vapour activity than LDPE, indicating that PA is less prone to swelling and plasticization by hexane, in agreement with its polar groups and semi-crystalline structure. On the other hand, the permeance of the TFC PA membranes strongly increases with decreasing permeate pressure. This might be due to occurrence of concentration polarization phenomena in the porous support of the TFC PA. This would result in higher flux at lower permeate pressure, because of a higher driving force, and also because of a non-negligible contribution of convective transport in the porous support. Over the whole activity range, the stagecut of hexane (Figure 4e, f and Figure S6) is higher at lower permeate pressure, which is also compatible with concentration polarization in the porous support layer. A strong concentration polarization was observed for the sweeping gas flow rate from 5 to $15 \mathrm{~mL}(\mathrm{STP}) \mathrm{min}^{-1}$. Therefore, the sweep flow rate was chosen as $20 \mathrm{~mL}(\mathrm{STP}) \mathrm{min}^{-1}$ nitrogen, where the concentration polarization was less significant. Such phenomenon is known for highly permeable membranes ${ }^{14,15}$ and can be limited by operation of the membranes at reduced permeate pressures.

Figure 5 shows the Arrhenius plots for both membranes, demonstrating opposite temperature influence on the logarithm of permeances. Interestingly, the activation energy is positive for the LDPE membrane, whereas it is negative for the PA membrane. It is well known that in dense membranes the transport of gases and vapours is governed by the solution-diffusion mechanism and the permeability is the product of these two terms:

$$
P=D \cdot S
$$

where both diffusion coefficient $D$ and solubility coefficient $S$ can be expressed as an exponential equation (combining Eq. (6) and Eq. (7)):

$$
\begin{aligned}
P & =P_{0} \cdot \exp \left[-\frac{E_{\mathrm{p}}}{R T}\right]= \\
& =D_{0} \cdot \exp \left[-\frac{E_{\mathrm{D}}}{R T}\right] \cdot S_{0} \cdot \exp \left[-\frac{\Delta H_{\mathrm{S}}}{R T}\right]
\end{aligned}
$$



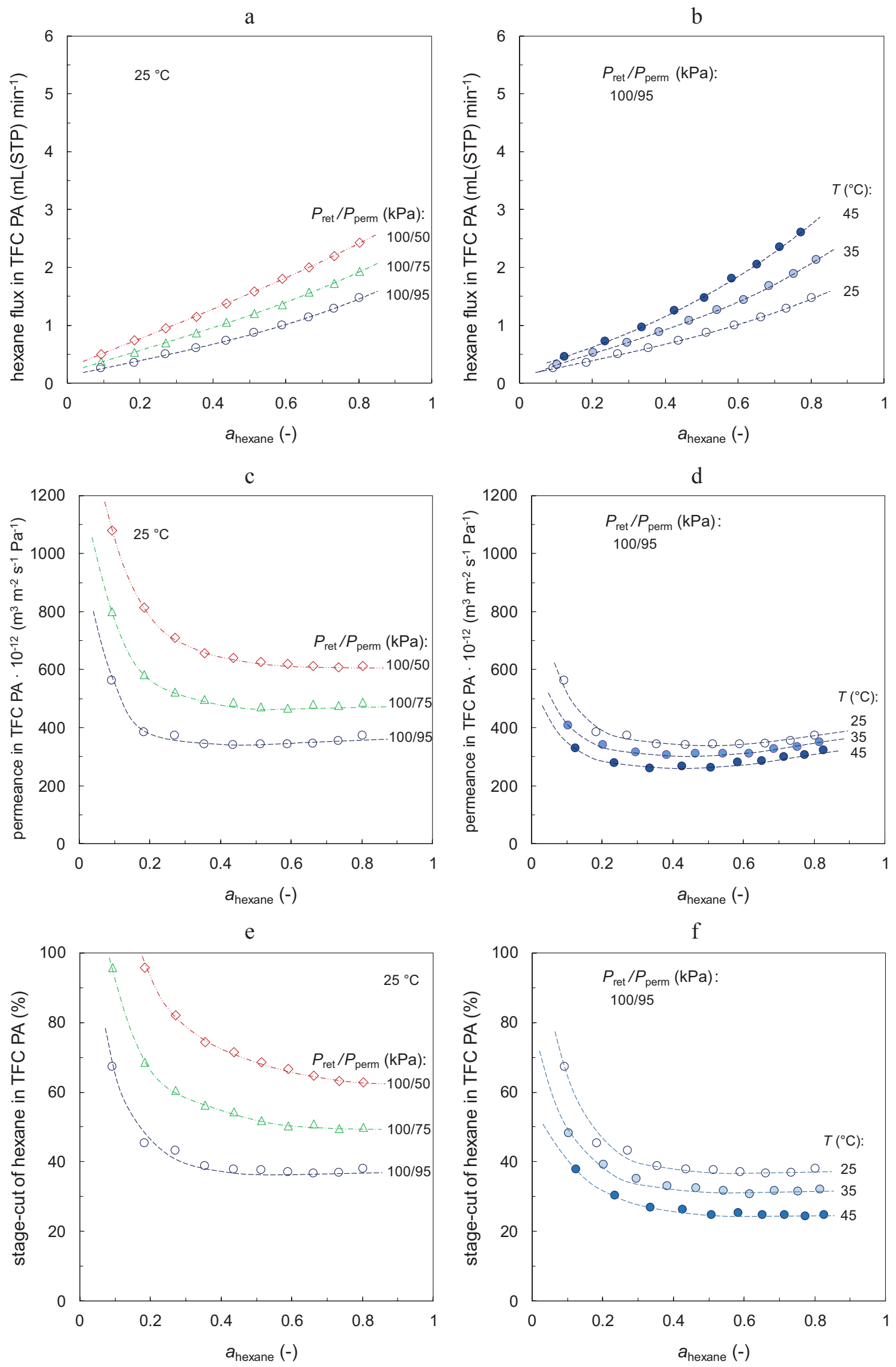

Fig. 4 - Results of permeation experiments with TFC PA (Toray) membrane: a, b) Hexane flux as a function of the hexane activity, temperature and trans-membrane pressure; $c, d)$ Hexane permeance as a function of the hexane activity, temperature and trans-membrane pressure; $e, f)$ Hexane stage-cut as a function of the hexane activity, temperature and trans-membrane pressure; The lines are intended as a guide to the eye. 


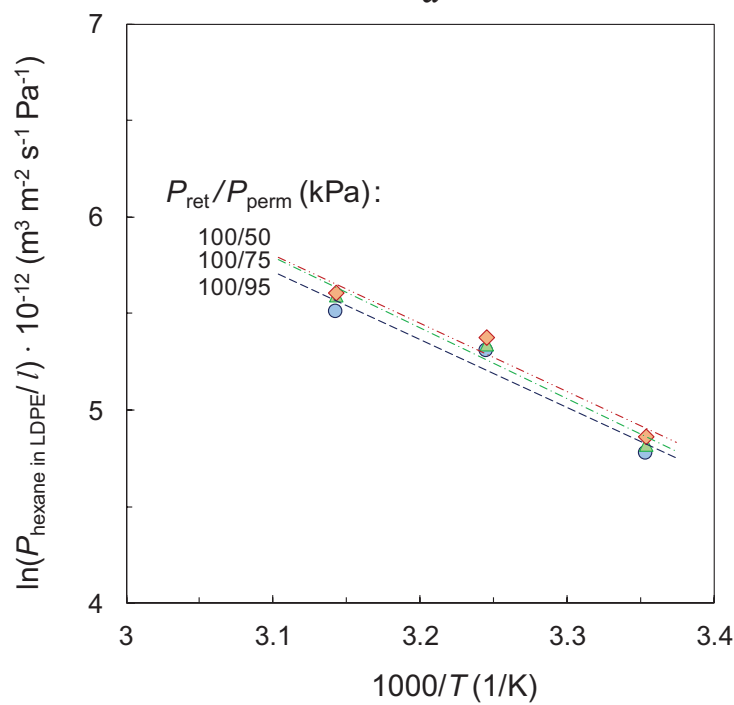

$\mathrm{b}$

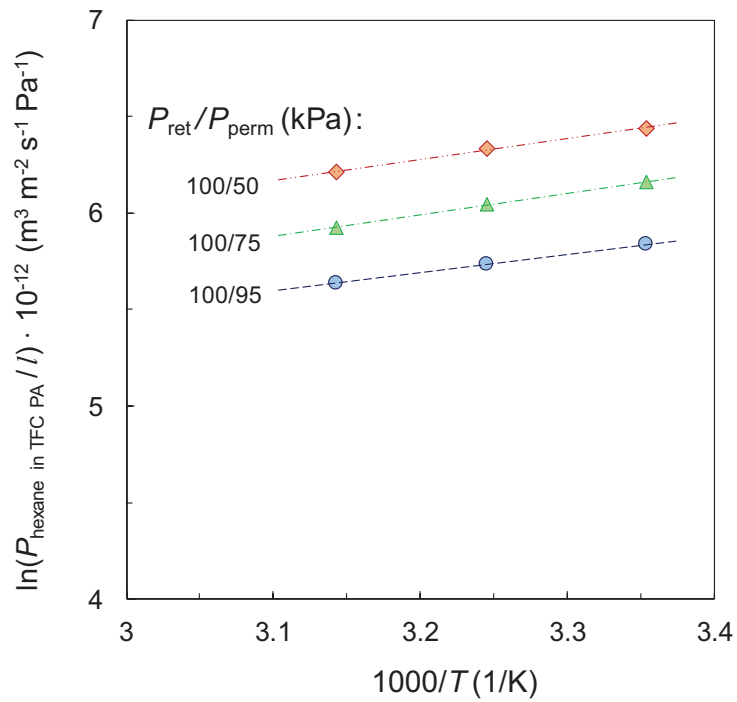

Fig. 5 - Arrhenius plots of hexane permeance at three different permeate pressures for a) LDPE and b) TFC PA membrane. The lines represent the linear least squares fit of the $\ln \left(P_{\text {hex }} / l\right)$ versus $1 / T$ according to the Arrhenius equation Eq. (6). The graphs are plotted for hexane vapour activity of 0.6 .

where activation energy for permeation $E_{\mathrm{p}}$ is a sum of activation energy for diffusion $E_{\mathrm{D}}$ and enthalpy of solubility $\Delta H_{\mathrm{S}}$. For diffusion, the exponent has the meaning of the activation energy of diffusion, which is indeed a thermally activated process, while for the solubility term, the exponent has the meaning of the dissolution enthalpy.

It is obvious from Figure 5 that a temperature increase favours the diffusivity of permeating species in a dense membrane, whereas it decreases the solubility. In the present case, apparently the increased diffusivity upon softening the LDPE matrix dominates the overall effect on the transport for the LDPE membrane, whereas the decrease in solubility dominates the effect of temperature in the PA membrane.

\section{Conclusions}

The hexane vapour permeation was studied for two kinds of commercially available membranes, namely, low density polyethylene (LDPE) and thin film composite polyamide (TFC PA) membranes. Two fundamentally different membranes were chosen to demonstrate the versatility and the sensitivity of a new permeation apparatus with in-line FID analysis. The hexane permeation was studied at the temperatures $25^{\circ} \mathrm{C}, 35^{\circ} \mathrm{C}$, and $45^{\circ} \mathrm{C}$, and hexane vapour activities ranging from 0.2 to 0.8 , and at trans-membrane pressures 5, 25, and $50 \mathrm{kPa}$, keeping the feed pressure always at $100 \mathrm{kPa}$ while the permeate pressures were 95,75 , or $50 \mathrm{kPa}$.

The LDPE membrane is highly efficient for hexane separation from light gases because even with a relatively thick membrane, nearly $25 \%$ of hexane was separated from the feed side to the permeate stream in a single step. Interestingly, the flux is hardly dependent on the permeate pressure, and thus on the trans-membrane pressure, with only a slight increase in flux at decreasing permeate pressure. At a given activity, the flux through LDPE increases almost four-fold upon increasing the temperature from 25 to $45{ }^{\circ} \mathrm{C}$. This is attributed to softening of the amorphous phase of the semi-crystalline LDPE. The nonlinear increase of the flux with activity indicates plasticization of the polymer by hexane and possibly a minor reduction in the crystallinity.

Analogous to the LDPE film, a thin film composite polyamide film (TFC PA) was tested. The PA skin layer on the porous support is much more permeable owing to its significantly thinner selective layer - nearly $95 \%$ of hexane is transferred from the feed side to the permeate stream in a single step at low activity. The flux increases almost linearly with activity, with a slight upward curvature. Since the PA is far away from any phase transition, its performance is less temperature-dependent than LDPE. The permeance of PA is much less dependent on the activity compared to LDPE, indicating that PA is much less prone to swelling and plasticization by hexane, in agreement with its polar groups and semi-crystalline structure. On the other hand, the permeance of the TFC PA membranes strongly increases with decreasing permeate pressure. This is likely due to the occurrence of concentration polarization phenomena in the porous support of the TFC. Such phenomenon is known for highly permeable membranes and can be limited by operation 
of the membranes at reduced permeate pressures. The opposite activation energies for hexane permeation in the thick LDPE film and the thin film composite PA membrane evidence the fundamentally different properties of these materials, while the overall results clearly demonstrate the feasibility of the use of in-line FID analysis in membrane permeation measurements.

\section{Supplementary Materials}

a

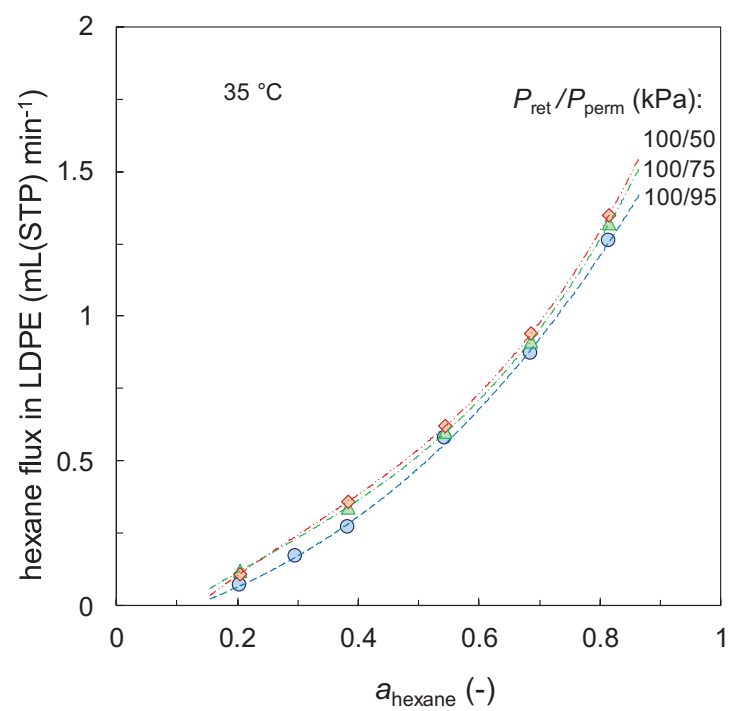

c

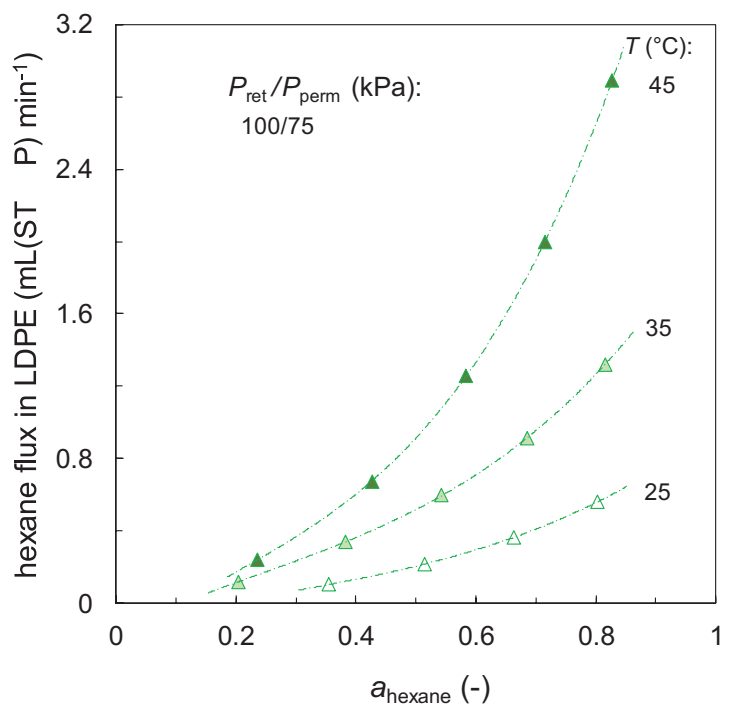

b

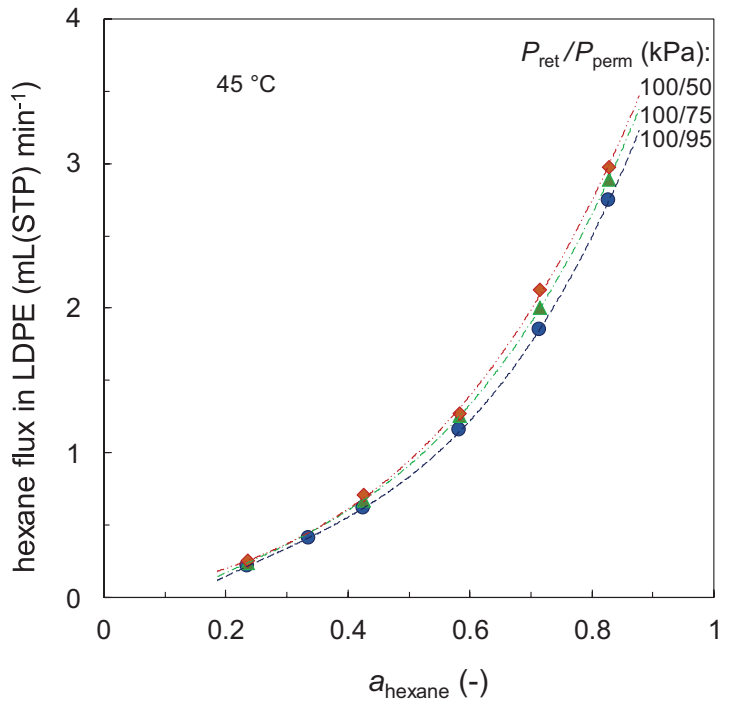

d

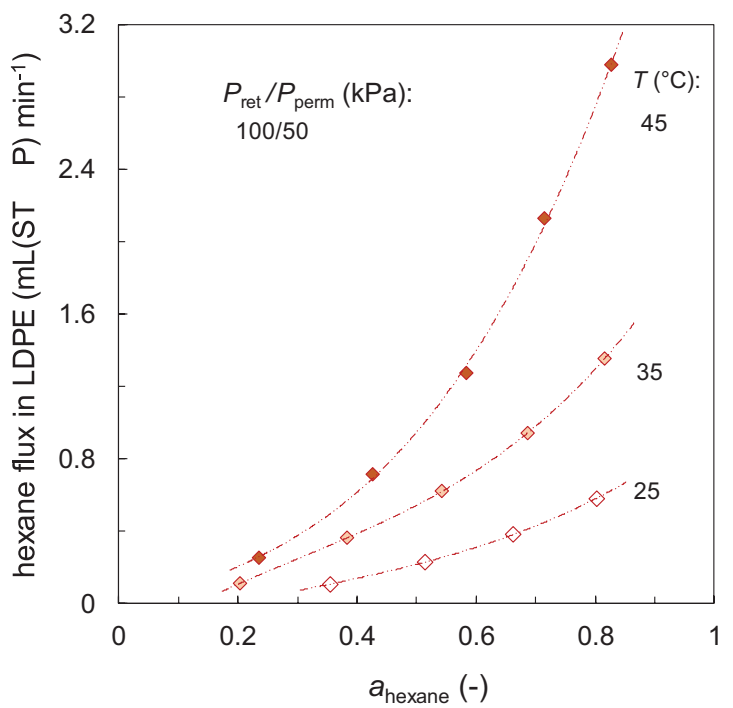

Fig. S 1 - Hexane flux in LDPE membrane: activity dependence at three different trans-membrane pressures at a) $35{ }^{\circ} \mathrm{C}$ and b) 45 ${ }^{\circ} \mathrm{C}$, activity dependence at three temperatures at trans-membrane pressure c) $25 \mathrm{kPa}$ and d) $50 \mathrm{kPa}$; The lines are intended as a guide to the eye. 
a



$\mathrm{C}$

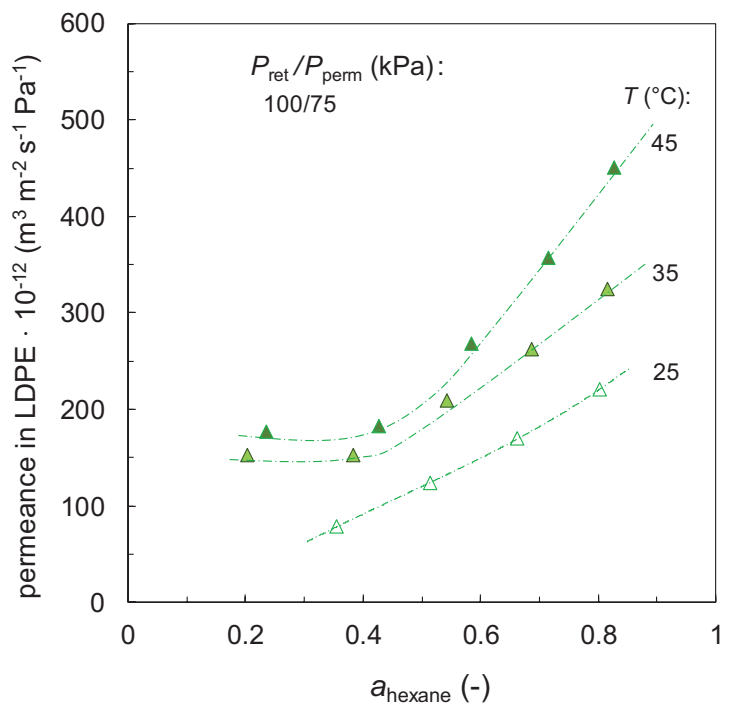

b

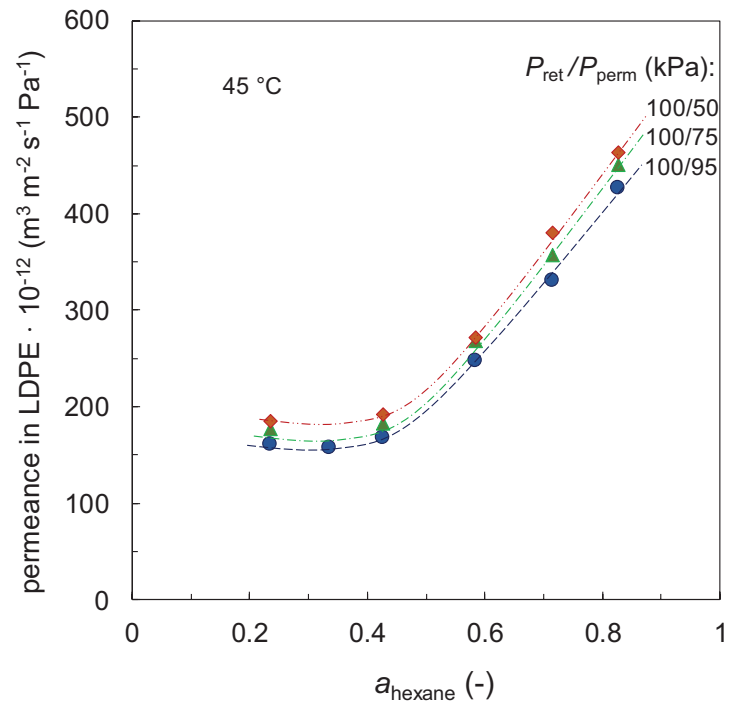

$\mathrm{d}$

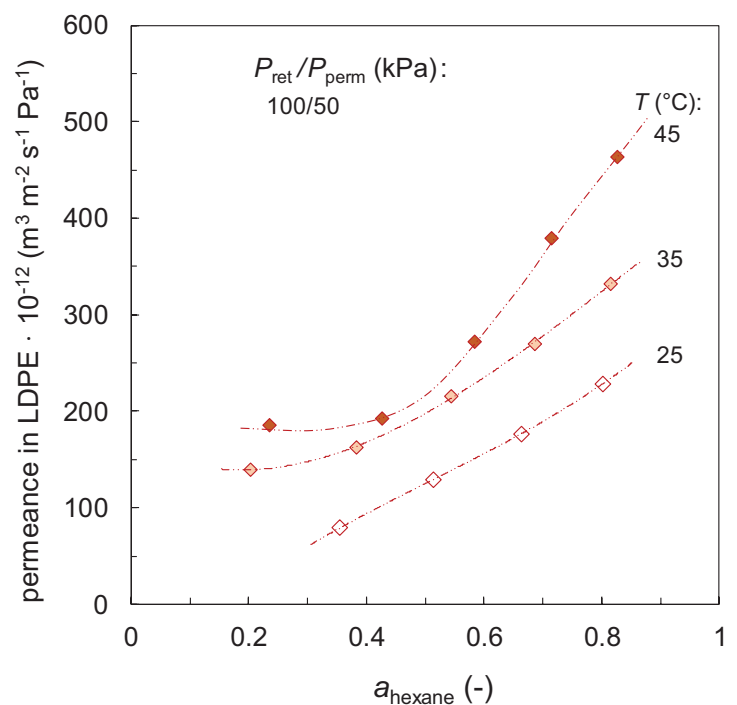

Fig. S 2 - Hexane permeance in LDPE membrane: activity dependence at three different trans-membrane pressures at a) $35{ }^{\circ} \mathrm{C}$ and b) $45{ }^{\circ} \mathrm{C}$, activity dependence at three temperatures at trans-membrane pressure c) $25 \mathrm{kPa}$ and d) $50 \mathrm{kPa}$; The lines are intended as a guide to the eye. 
a

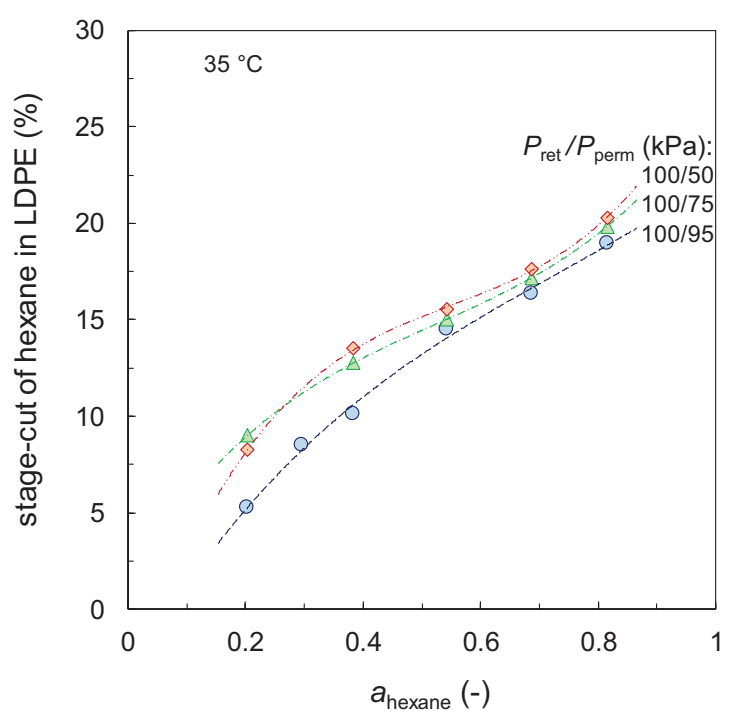

C

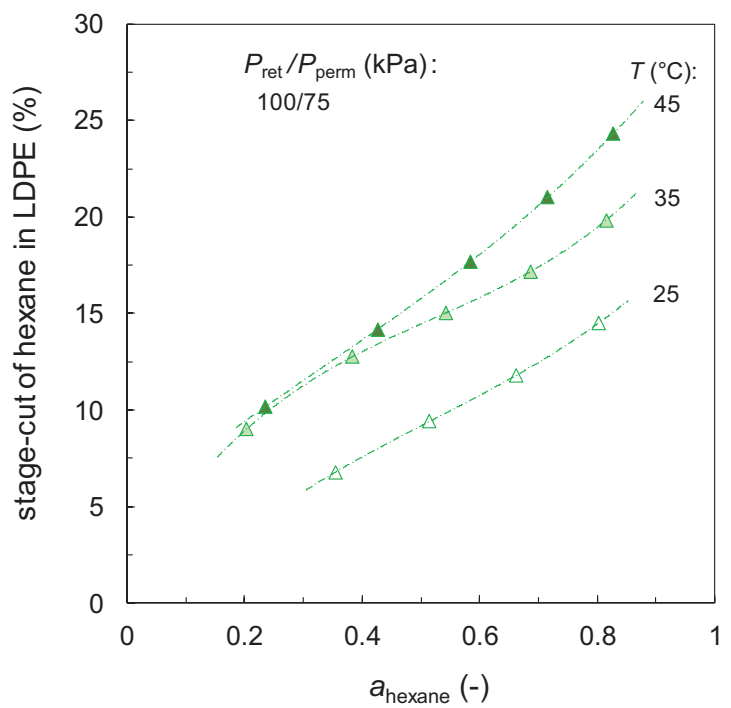

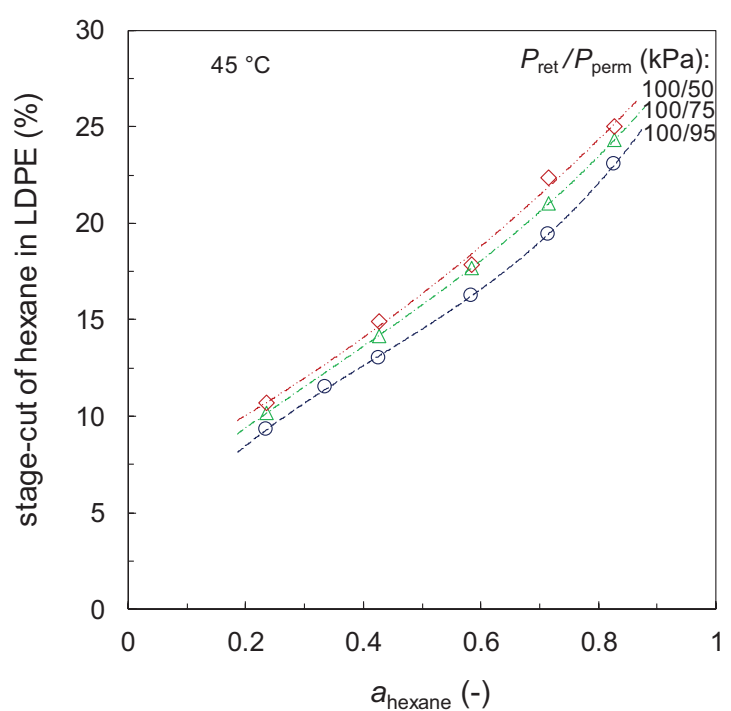

d

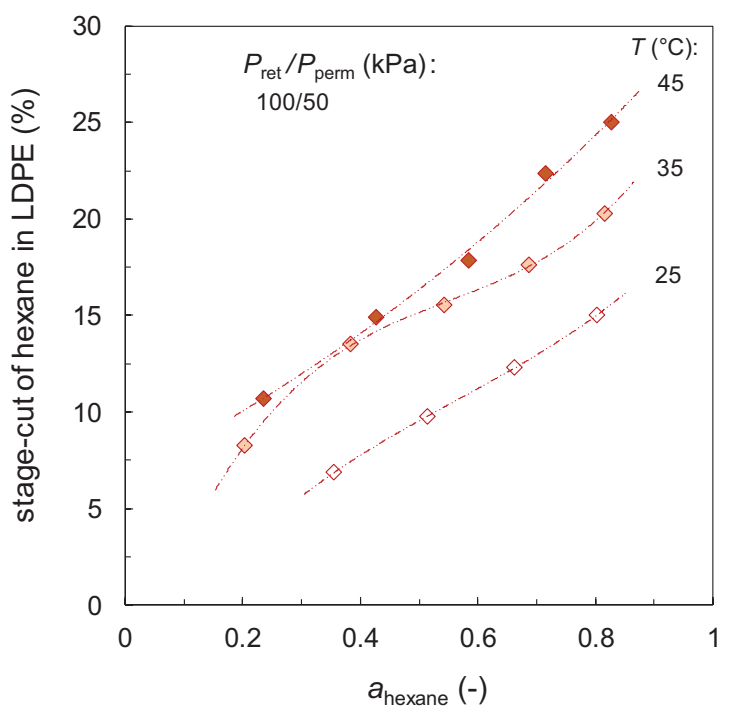

Fig. S 3 - Hexane stage-cut in LDPE membrane: activity dependence at three different trans-membrane pressures at a) $35{ }^{\circ} \mathrm{C}$ and b) $45{ }^{\circ} \mathrm{C}$, activity dependence at three temperatures at trans-membrane pressure c) $25 \mathrm{kPa}$ and d) $50 \mathrm{kPa}$; The lines are intended as a guide to the eye. 
a
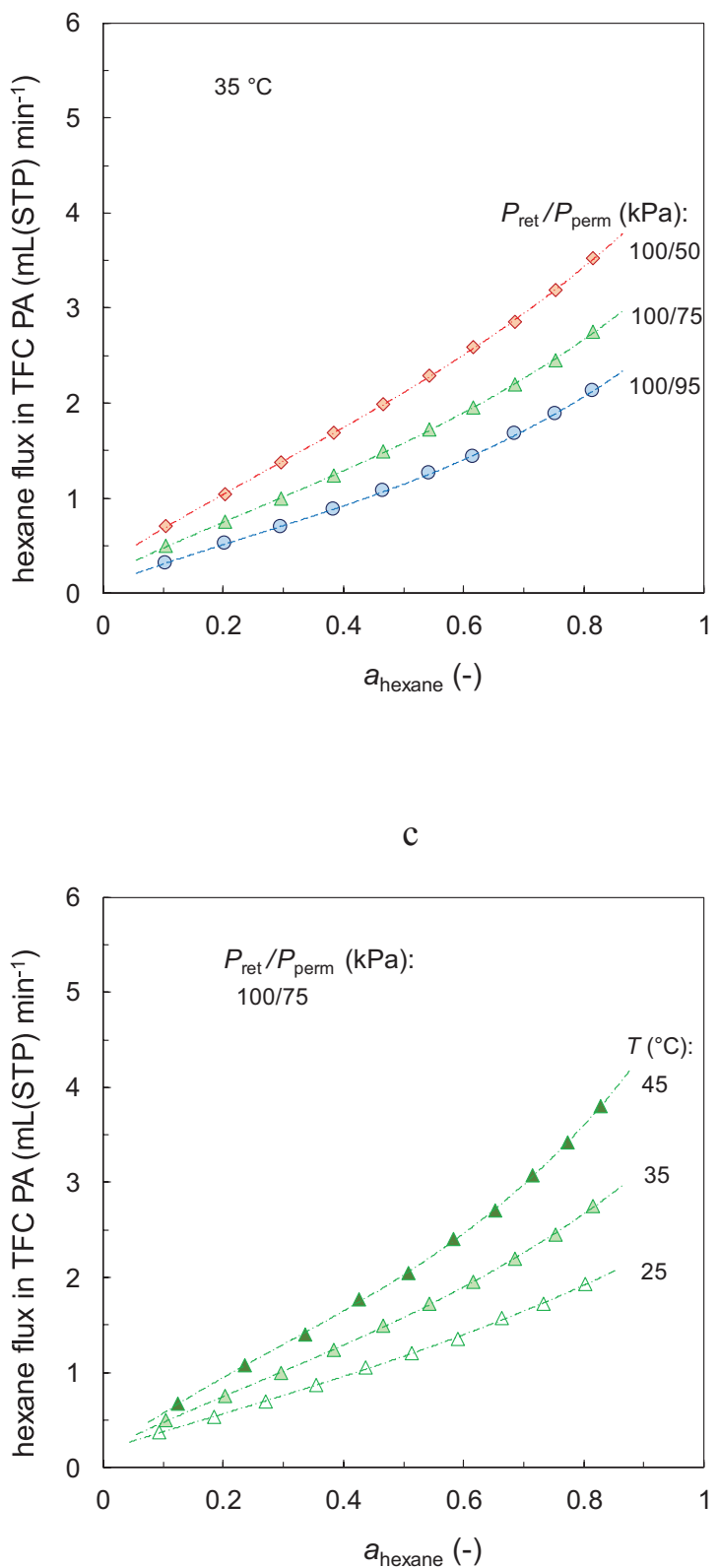

b

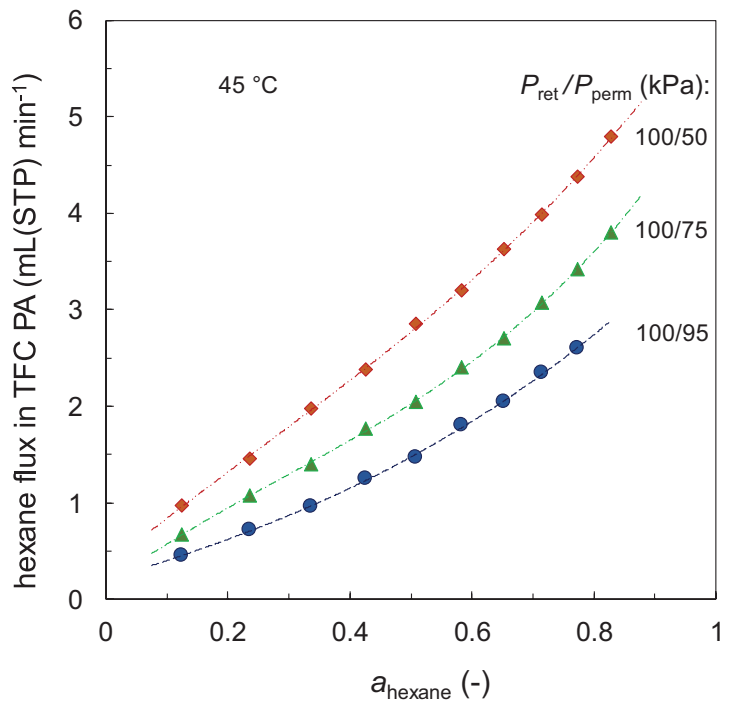

d

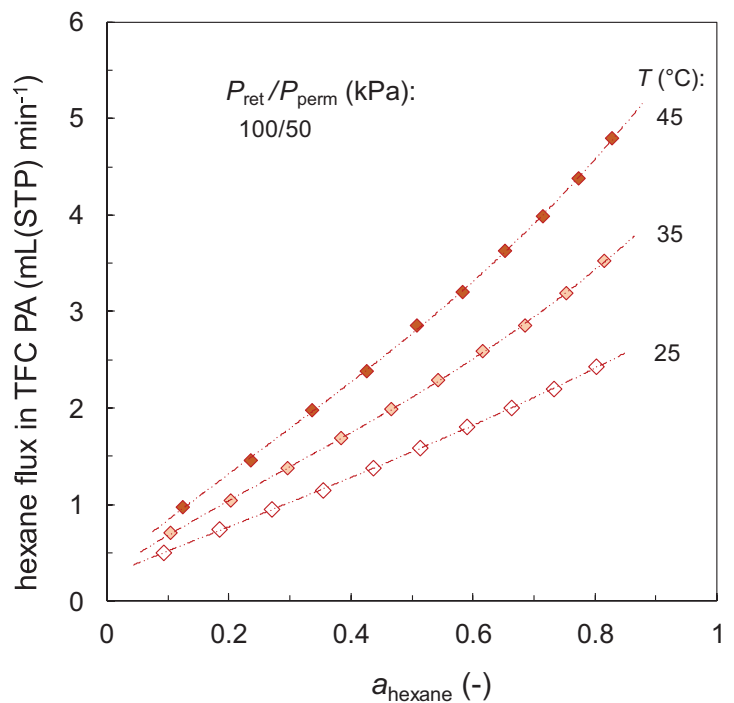

Fig. S 4 - Hexane flux in TFC PA (Toray) membrane: activity dependence at three different trans-membrane pressures at a) $35{ }^{\circ} \mathrm{C}$ and b) $45{ }^{\circ} \mathrm{C}$, activity dependence at three temperatures at trans-membrane pressure c) $25 \mathrm{kPa}$ and d) $50 \mathrm{kPa}$; The lines are intended as a guide to the eye. 
a

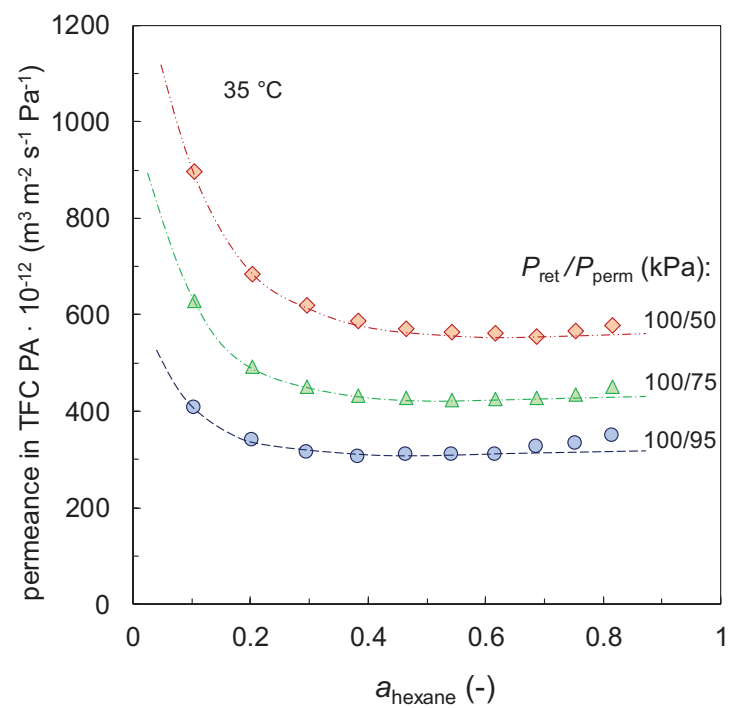

C

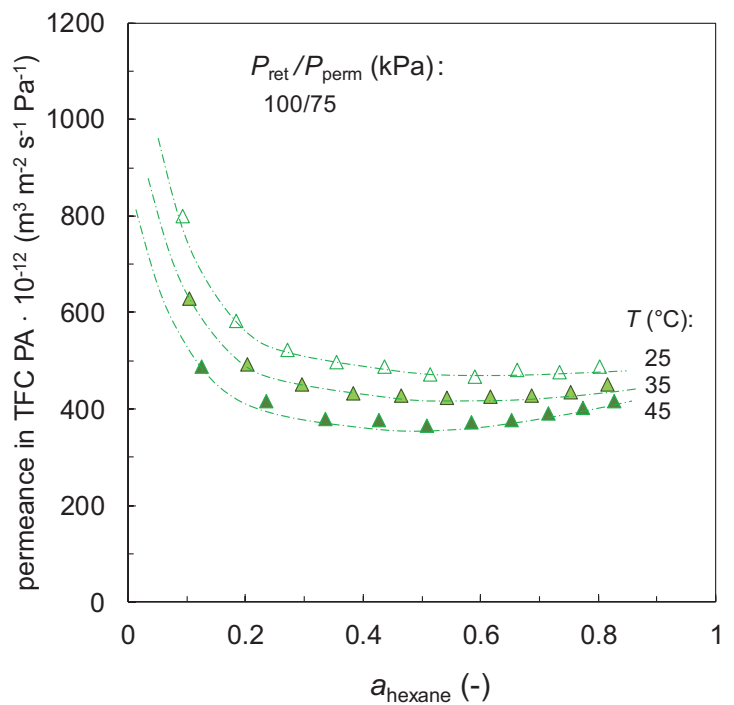

b

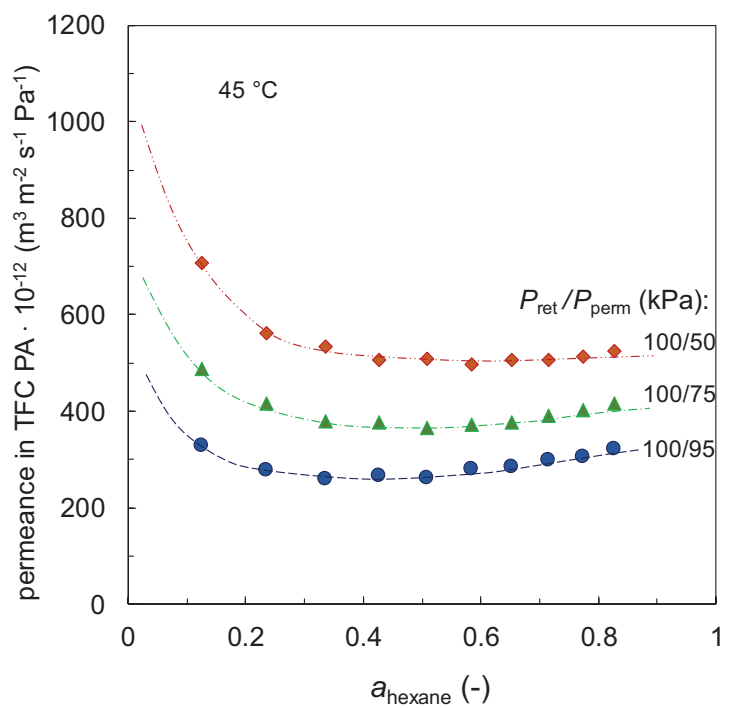

d

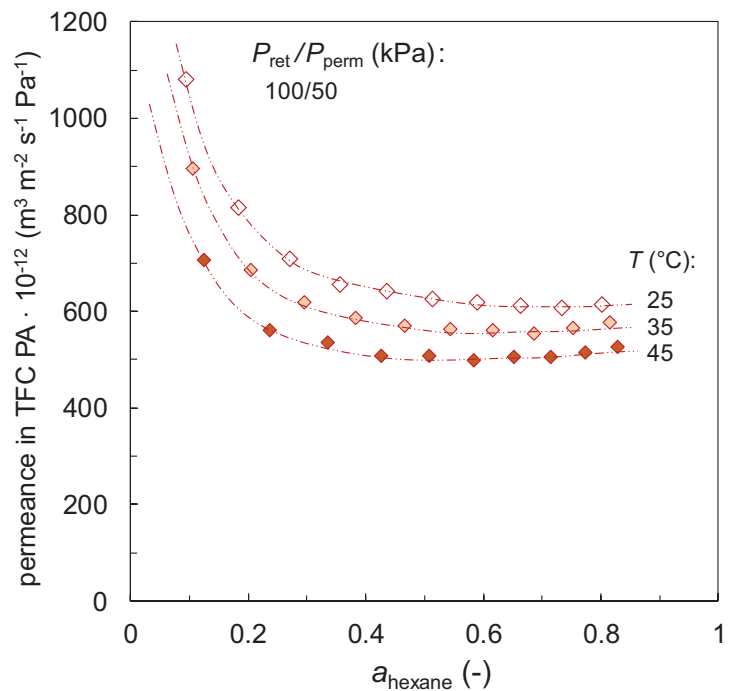

Fig. S 5 - Hexane permeance in TFC PA (Toray) membrane: activity dependence at three different trans-membrane pressures at a) $35^{\circ} \mathrm{C}$ and b) $45^{\circ} \mathrm{C}$, activity dependence at three temperatures at trans-membrane pressure c) $25 \mathrm{kPa}$ and d) $50 \mathrm{kPa}$; The lines are intended as a guide to the eye. 
a
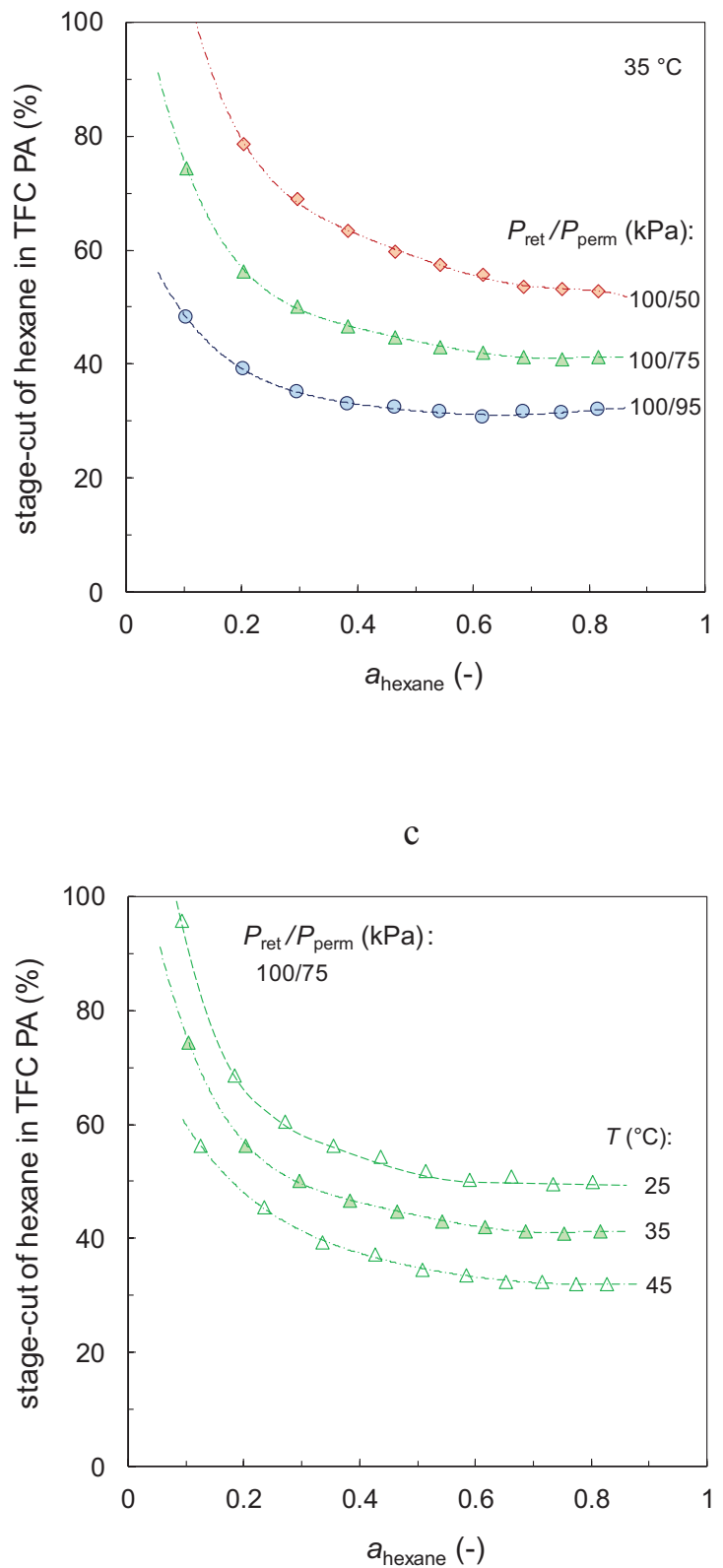

b

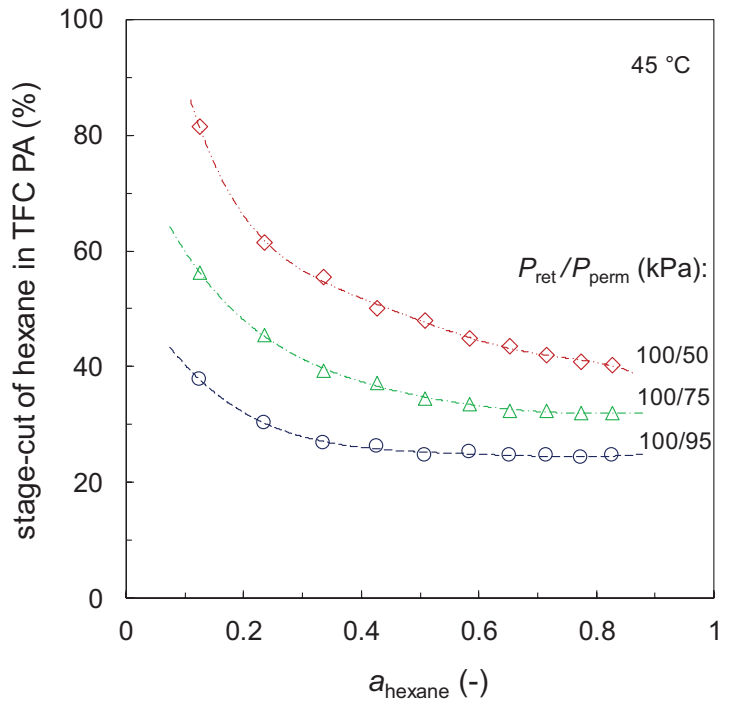

d

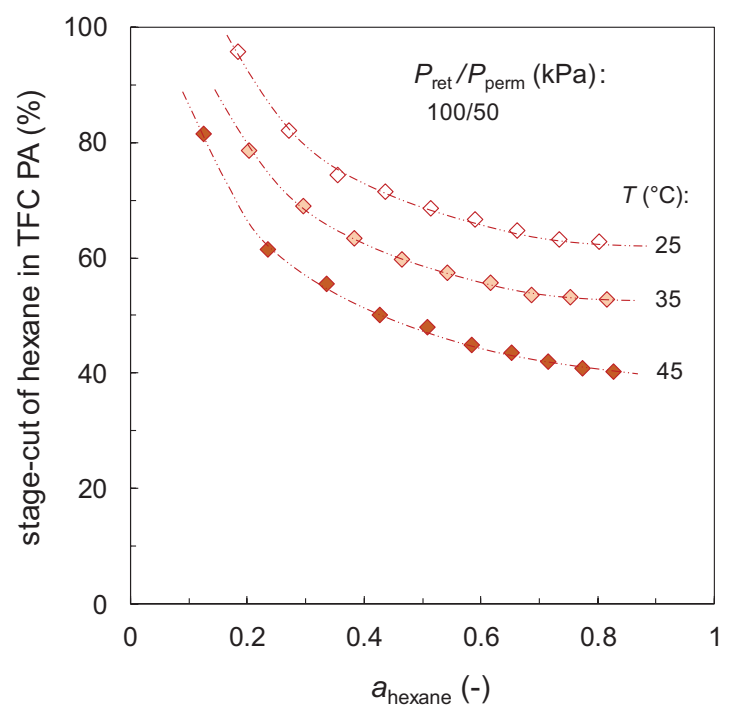

F ig. S 6 - Hexane stage-cut in TFC PA (Toray) membrane: activity dependence at three different trans-membrane pressures at a) 35 ${ }^{\circ} \mathrm{C}$ and b) $45{ }^{\circ} \mathrm{C}$, activity dependence at three temperatures at trans-membrane pressure c) $25 \mathrm{kPa}$ and d) $50 \mathrm{kPa}$; The lines are intended as a guide to the eye. 


\section{ACKNOWLEDGEMENTS}

This research was supported by the Ministry of Education, Youth and Sports of the Czech Republic (project No. LD14094) and the CNR-CAS bilateral agreement 2016-2018 "Innovative polymeric membranes for pervaporation and advanced gas and vapour separations".

\section{References}

1. George, S. C., Thomas, S., Transport phenomena through polymeric system, Prog. Polym. Sci. 26 (2001) 985. doi: https://doi.org/10.1016/S0079-6700(00)00036-8

2. Liu, Y., Feng, X., Lawless, D., Separation of gasoline vapor from nitrogen by hollow fiber composite membranes for VOC emission control, J. Membr. Sci. 271 (2006) 114. doi: https://doi.org/10.1016/j.memsci.2005.07.012

3. Rebollar-Pérez, G., Carretier, E., Lesage, N., Moulin, P., Vapour permeation of VOC emitted from petroleum activities: Application for low concentrations, J. Ind. Eng. Chem. 18 (2012) 1339. doi: https://doi.org/10.1016/j.jiec.2012.01.039

4. Sommer, S., Melin, T., Influence of operation parameters on the separation of mixtures by pervaporation and vapor permeation with inorganic membranes. Part 2: Purely organic systems, Chem. Eng. Sci. 60 (2005) 4525. doi: https://doi.org/10.1016/j.ces.2005.02.070

5. Wijmans, J. G., Baker, R. W., The solution-diffusion model: a review, J. Membr. Sci. 107 (1995) 1. doi: https://doi.org/10.1016/0376-7388(95)00102-I

6. Choi, S.-H., Kim, J.-H., Lee, S.-B., Sorption and permeation behaviors of a series of olefins and nitrogen through PDMS membranes, J. Membr. Sci. 299 (2007) 54. doi: https://doi.org/10.1016/j.memsci.2007.04.022

7. Liu, L., Chakma, A., Feng, X., A novel method of preparing ultrathin poly(ether block amide) membranes, J. Membr. Sci. 235 (2004) 43. doi: https://doi.org/10.1016/j.memsci.2003.12.025

8. Friess, K., Jansen, J. C., Vopička, O., Randová, A., Hynek, V., Šipek, M., Bartovská, L., Izák, P., Dingemans, M., De- wulf, J., Van Langenhove, H., Drioli, E., Comparative study of sorption and permeation techniques for the determination of heptane and toluene transport in polyethylene membranes, J. Membr. Sci. 338 (2009) 161.

doi: https://doi.org/10.1016/j.memsci.2009.04.030

9. Pilnáček, K., Vopička, O., Lanč, M., Dendisová, M., Zgažar, M., Budd, P. M., Carta, M., Malpass-Evans, R., McKeown, N. B., Friess, K., Aging of polymers of intrinsic microporosity tracked by methanol vapour permeation, J. Membr. Sci. 520 (2016) 895. doi: https://doi.org/10.1016/j.memsci.2016.08.054

10. Moravkova, L., Vopicka, O., Vejrazka, J., Vychodilova, H., Sedlakova, Z., Friess, K., Izak, P., Vapour permeation and sorption in fluoropolymer gel membrane based on ionic liquid 1-ethyl-3-methylimidazolium bis(trifluoromethylsulfonyl)imide, Chem. Pap. 68 (2014) 1739.

doi: https://doi.org/10.2478/s11696-014-0623-x

11. Vopička, O., Morávková, L., Vejražka, J., Sedláková, Z., Friess, K., Izák, P., Ethanol sorption and permeation in fluoropolymer gel membrane containing 1-ethyl-3-methylimidazolium bis(trifluoromethylsulphonyl)imide ionic liquid, Chem. Eng. Process 94 (2015) 72. doi: https://doi.org/10.1016/j.cep.2015.02.008

12. Simcik, M., Ruzicka, M. C., Karaszova, M., Sedlakova, Z., Vejrazka, J., Vesely, M., Capek, P., Friess, K., Izak, P., Polyamide thin-film composite membranes for potential raw biogas purification: Experiments and modelling, Sep. Purif. Technol. 167 (2016) 163. doi: https://doi.org/10.1016/j.seppur.2016.05.008

13. Baker, R. W., Membrane Technology and Applications, John Wiley \& Sons, Ltd, 2012. doi: https://doi.org/10.1002/9781118359686

14. Puguan, J. M. C., Kim, H.-S., Lee, K.-J., Kim, H., Low internal concentration polarization in forward osmosis membranes with hydrophilic crosslinked PVA nanofibers as porous support layer, Desalination 336 (2014) 24. doi: https://doi.org/10.1016/j.desal.2013.12.031

15. Arena, J. T., McCloskey, B., Freeman, B. D., McCutcheon, $J$. R., Surface modification of thin film composite membrane support layers with polydopamine: Enabling use of reverse osmosis membranes in pressure retarded osmosis, $\mathrm{J}$. Membr. Sci. 375 (2011) 55. doi: https://doi.org/10.1016/j.memsci.2011.01.060 